\title{
Brain Complications with Influenza Infection in Children
}

\author{
Qinglian Chen', Peiqing Li', Suyun Li1, Weiqiang Xiao², Sida Yang3, Hui Lu${ }^{4 *}$ \\ ${ }^{1}$ Guangzhou Medical University, Guangzhou, China \\ ${ }^{2}$ Department of Radiology, Guangzhou Women and Children's Medical Center, Guangzhou Medical University, Guangzhou, China \\ ${ }^{3}$ Department of Pediatric Neurology, Guangzhou Women and Children's Medical Center, Guangzhou Medical University, \\ Guangzhou, China \\ ${ }^{4}$ Institute of Pediatrics, Guangzhou Women and Children’s Medical Center, Guangzhou Medical University, Guangzhou, China \\ Email: *gzluhui@163.net
}

How to cite this paper: Chen, Q.L., Li, P.Q., Li, S.Y., Xiao, W.Q., Yang, S.D. and Lu, H. (2020) Brain Complications with Influenza Infection in Children. Journal of Behavioral and Brain Science, 10, 129-152. https://doi.org/10.4236/jbbs.2020.103008

Received: February 5, 2020

Accepted: March 21, 2020

Published: March 24, 2020

Copyright ( 2020 by author(s) and Scientific Research Publishing Inc. This work is licensed under the Creative Commons Attribution International License (CC BY 4.0).

http://creativecommons.org/licenses/by/4.0/

\begin{abstract}
Objectives: To summarize the characteristics and research progress of influenza-associated brain complications in children and provide references for early diagnosis and brain protection treatment. Methods: Studied published articles of influenza-associated neurocomplications in children from PubMed and summarizes them from epidemiology, clinical manifestations, diagnosis and treatment, and basic research progress. Results: Common brain complications in flu-children include febrile seizures, influenza-associated encephalopathy (IAE), acute or post-influenza encephalitis, and the most severe condition is acute necrotizing encephalopathy (ANE). However, the mechanism and relevant factors of influenza-associated brain damage have not been elucidated. Conclusion: Influenza could be accompanied by various brain lesion complications in dif ferent stages of the disease, some of which are life-threatening or leave severe neurological sequelae, such as ANE. Due to different brain injury mechanisms, specific early diagnosis and brain protection treatment for different complications are unclear or unanimous. Therefore, further classification and basic research are needed.
\end{abstract}

\section{Keywords}

Brain, Lesions, Risk Factor, Influenza, Children

\section{Introduction}

Influenza in children is a major cause of morbidity and mortality worldwide. Annual epidemics in adults and children are associated with an estimated 3 - 5 million cases of severe illness, and about 290,000 - 650,000 deaths. Influenza in- 
fection is seasonal in temperate countries, with peaks during the winter months, but it sustains activity throughout the year in tropical climates [1]. Among the brain complications of influenza, the most serious is acute necrotizing encephalopathy (ANE), which has a mortality rate of about $30 \%$. We review the published articles of influenza-associated neurocomplications in children from PubMed, and summarizes them from epidemiology, clinical manifestations, diagnosis and treatment, and basic research progressing, in order to provide references for early diagnosis and brain protection treatment during influenza seasons.

Influenza is an acute infectious disease caused by influenza viruses, which spreads between people through droplets and contact, with fast and high transmission. It is mainly spread via children, who are generally more susceptible to infection. Influenza outbreaks occur every year at various scales, which normally has an incubation period of 1 - 4 days ( 2 days on average). According to the annual statistic report of infectious diseases from China CDC, the incidence of influenza has been increasing since 2014 (Figure 1). Influenza-infected persons may exhibit typical symptoms of influenza including acute fever, headache, myalgia and discomfort, with respiratory symptoms, or not show any typical clinical features. Symptoms in young children are characterized by high fever, febrile seizures, and gastrointestinal complaints such as nausea, vomiting, diarrhoea, and loss of appetite. Common complications of influenza can affect respiratory, digestive, muscular, cardiovascular, neurological and other systems. In the course of the disease, concomitant infection may occur by Streptococcus pneumoniae, Staphylococcus aureus, Haemophilus-influenzae infection, and even septic shock [2]. Factors related to increased mortality rate include [3] [4]: Children under 5 years old (Children under 2 years old are prone to higher incidence of serious complications); Persons over 65 years old; Persons with the following diseases or symptoms: chronic respiratory diseases, cardiovascular diseases (excluding hypertension), kidney disease, liver disease, blood system diseases, nervous system and neuromuscular diseases, metabolic and endocrine diseases, inhibition of immune responses (including low immune function induced by the use of immunosuppressants or HIV infection); Obesity ( BMI greater than 30); Pregnancy and perinatal women; Concomitant infection by Staphylococcus aureus or Streptococcus pneumoniae [2]. It is worth noting that, omitting pediatric patients with high-risk conditions, about $1 / 2$ of the pediatric patients in death cases have no high-risk conditions [5].

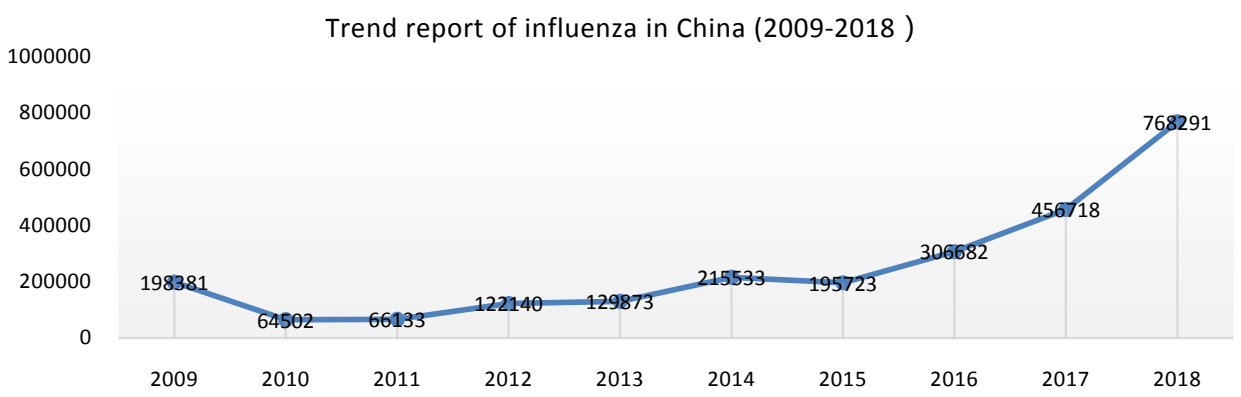

Figure 1. Trend report of influenza in China (2009-2018). 
Children without high-risk medical conditions were more likely to die before hospital admission and within 3 days of symptom onset than those with high-risk medical conditions [5].

\section{Influenza Virology}

Influenza viruses are negative-sense, single-stranded RNA (-ssRNA) viruses of the family Orthomyxoviridae family. It can be constructed three parts from the outside into the inside: capsule, matrix protein and core. Influenza virus is classified into influenza viruses $\mathrm{A}, \mathrm{B}$ and $\mathrm{C}$ according to different antigenicity of nucleoprotein. Based on the antigenicity of Hemagglutinin (HA) and neuraminidase (NA) on the capsule, it can be further divided into different subtypes denoted by numbers, such as H1N1. HA allows the influenza virus to bind to the Hemagglutinin receptor on the surface of host cell, while NA allows the detachment of mature virion from the host cell, which plays a key role in infecting other host cells. Epidemiological models reflect antigenic transformation and antigenic drift of $\mathrm{HA}$ and NA surface proteins [6] [7].

\section{Neurologic Complications Associated with Influenza}

Central nervous system (CNS) complications may occur in influenza-affected children, and with higher risk ( $<4$ years old) in young children with basic diseases. Neurologic complications of influenza include febrile convulsion, encephalopathy, acute encephalitis, aseptic meningitis, acute cerebellar ataxia, myelitis, Guillain-Barre' syndrome, acute disseminated encephalomyelitis (ADEM), acute mental status change, and occasionally cerebrovascular disease, such as cerebral infarction [8]-[13]. Along with reduced use of aspirin in children, the incidence rate of Reye syndrome decreases.

\section{Influenza-Associated Encephalopathy (IAE)}

\subsection{Epidemiology and Susceptible Population}

IAE is a clinical syndrome accompanied by central nervous system dysfunction during acute influenza, which is more common in young children. The incidence of IAE peaks during 1 to 5 years old children, which accounts for $81.8 \%$ of total [5], therefore 1 to 6 years old influenza patients are targeted population of prevention and treatment.

\subsection{Clinical Manifestation}

Patients with IAE have symptoms of convulsions, acute cognitive impairment, acute disturbance of consciousness (ADOC), and coma with varying severity [14] [15] [16]. In a recent study showed that in children under 2 years of age altered consciousness was the most frequent neurological manifestation while respiratory symptoms were present at admission; younger children also required intensive care support more frequently; and the median time from onset of respiratory signs to onset of neurological manifestations was $24 \mathrm{~h}$ [17]. 


\subsection{Laboratory Inspection}

There is no specific laboratory indicator of IAE. Liver dysfunction is symptom commonly seen in IAE patients, including ALT, AST, and LDH; thrombocytopenia and coagulation abnormalities can also occur. All these factors are associated with poor prognosis [9]. Hyperammonemia and hypoglycemia is presented in around $11 \%$ of IAE cases. No viruses could be detected in CSF in most cases, and cell numbers and proteins level of CSF are normal in around $90 \%$ of IAE cases. In most cases, IAE are caused by influenza A virus infections or mixed infections of influenza A and influenza B viruses, while cases infected merely by influenza B viruses only count for $10 \%$.

\subsection{Imaging Examination}

Brain imaging examinations were conducted in IAE patients, including computed tomography (CT) scan and magnetic resonance imaging (MRI). Imaging changes were found such as cerebral edema, hemorrhage, or bilateral thalamic lesions, and these neuroimaging abnormalities are associated with poor prognosis [18] [19]. Mild encephalopathy patients were also diagnosed with reversible corpus callosum lesion (MERS) [20] [21]. According to MRI and CT results, Kimura et al. divided influenza related brain lesions into 5 categories [22]: normal (category 1); diffuse involvement of cerebral cortex (category 2); diffuse brain edema (category 3); symmetrical involvement of the thalamus (category 4); and postinfectious focal encephalitis (category 5 ).

\subsection{Pathology}

Vascular injuries in nervous system were found in cadaveric tissue pathology, including intracerebral vascular occlusion, micro thrombus formation, perivascular haemorrhage and edema, but no inflammatory changes were observed in mononuclear cell infiltration [23] [24]. Clasmatodendrosis was distributed diffusely in the IAE brains in close association with synapses and was not caused by astrocyte autophagy [25].

\subsection{Diagnostic Criteria, Treatment and Outcome}

The diagnostic and therapeutic criteria of IAE are shown in Table 1 [18] [23] [24], include: 1) Acute onset with positive detection of influenza virus; 2) Accompanied by sudden neurological symptoms; 3) Most cerebrospinal fluid cells are normal, or with slight protein elevation; 4) Imaging supports encephalopathy change, Including head CT and MRI, CT or MRI can find brain edema, bleeding or bilateral thalamic lesions and other imaging changes; diffuse slow wave in EEG. There was a study inclusion the patient with IAE included either presented with status epilepticus (for 30 min or longer) or reached level 2 diagnostic certainty on the Brighton encephalopathy score [26] [27]. Another author defines encephalopathy as altered mental status lasting $\geq 24$ hours [28]. Commonly used treatment options are oseltamivir, empiric 3rd generation cephalosporins, IV-Ig, 
Table 1. Diagnostic and therapeutic criteria of IAE.

\begin{tabular}{|c|c|c|}
\hline & Criteria & Description \\
\hline 1 & Positive diagnosis of influenza & virus antigen and nucleic acid, virus isolation \\
\hline 2 & Clinical manifestations & $\begin{array}{l}\text { Acute onset with sudden neurological symptoms, such as } \\
\text { seizures, rapid cognitive impairment, mental changes, loss of } \\
\text { consciousness, coma }\end{array}$ \\
\hline 3 & Laboratory & $\begin{array}{l}\text { CSF in most IAE cases has not detected virus; most } \\
\text { cerebrospinal fluid cells and protein are normal, or with slight } \\
\text { protein elevation }\end{array}$ \\
\hline 4 & Brain imaging & $\begin{array}{l}\text { Imaging supports encephalopathy change; diffuse slow wave } \\
\text { in EEG }\end{array}$ \\
\hline & & $\begin{array}{l}\text { a) Antiviral treatment within } 48 \text { hours of onset: Oseltamivir, } \\
\text { peramivir, Zanamivir, etc. } \\
\text { b) High dose of gamma globulin and hormone shock therapy }\end{array}$ \\
\hline 5 & Best treatment practice & $\begin{array}{l}\text { c) Reduced brain metabolism } \\
\text { d) Plasma exchange therapy is recommended when DIC } \\
\text { and/or MOF are present } \\
\text { e) Intensive care, supportive care, etc. }\end{array}$ \\
\hline
\end{tabular}

corticosteroids, and plasmapheresis were recorded, but the evidence for its effectiveness is limited. IAE are heterogeneous with varied clinical features, and outcome related to magnetic resonance imaging changes [29].

\subsection{Basic Research Progress}

Extensive disruption of astrocytic projections (clasmatodendrosis) was detected in H1N1-associated deceased patients by anti-glial fibrillary acidic protein (GFAP) immunostaining of brain tissue [30]. Reduced spine density of microglia, abnormal proliferation of glial cells, demyelinating changes of nerve fiber in brain tissue pathology were also reported in previous studies, while no lymphocyte and neutrophil infiltration were found [31]; and close association with synapses and was not caused by astrocyte autophagy [25]. These pathological phenomena imply that influenza viruses can damage brain cells through non-direct damage. Serum level of neutrophil elastase was also elevated in IAE patients [32]. Research of Hosoya and colleagues indicates that elevated serum level of cytochrome c oxidase in influenza patients implies incidence of influenza-associated encephalopathy: increased level of cytochrome c oxidase above $45 \mathrm{ng} / \mathrm{ml}$ or higher threshold implies a poor prognosis of influenza-associated encephalopathy; sensitivity of $93 \%$ and specificity of $100 \%$ suggests apoptosis following virus infection [33].

\section{Influenza-Associated Acute Necrotizing Encephalopathy (IANE)}

\subsection{Epidemiology and Susceptible Population}

IANE is an acute non-inflammatory encephalopathy commonly, which is often marked by a sudden, explosive attack and occurs mostly in young children under 5-year-old. 


\subsection{Clinical Manifestation}

Typical clinical manifestation of IANE is rapid progression to encephalopathy, coma or death within 1 to 2 days from the onset (usually within 24 hours from the onset of fever) [14] [15] [34]. Generally, the clinical stages are: 1) Prodromal stage-most children have respiratory, gastrointestinal infections such as fever, cough, vomiting, diarrhea; 2) Early-stage of acute encephalopathy-within 1 to 2 days after the prodromal stage (Usually within 24 hours after the onset of fever) rapid progress to high fever, frequent convulsions, ADOC (Acute disturbance of consciousness), and the average time from fever to the appearance of neurological symptoms is 1.7 days; 3 ) Acute necrotizing encephalopathy stage-deterioration of neurological symptoms occurred rapidly, such as status epilepticus, deep co$\mathrm{ma}$, and multiple organ failure even death; 4) recovery stage-starts from the recovery of consciousness in 6 - 10 days after the onset of brain symptoms, which often lasts for several months, and very few patients can fully recover. It is possible that $<4$ years of age, repeated seizures, ADOC, and Babinski's sign might be the high-risk factors for IANE [4].

\subsection{Laboratory Inspection}

There is also no specific laboratory indicator of IANE [8] [16] [35]. Blood tests show increased white blood cells, decreased platelets, increased CRP and ESR, prolonged APTT, and decreased FIB. Biochemical indicators show liver enzymes (ALT, AST and LDH) significantly increased and hypoalbuminemia. CSF protein levels are abnormally elevated. However, these indicators are not specific for diagnosis. A study by Ashley pointed out that the independent factors associated with death included blood AST > $500 \mathrm{U} / \mathrm{L}$, glucose $>150 \mathrm{mg} / \mathrm{dL}$, hematuria or proteinuria, and positive RANBP2 mutation detection [15].

\subsection{Imaging Examination}

Patients with ANE display symmetric necrosis of the thalamus and other deep brain structures, particularly in the brain stem, surrounding white matter and cerebellar medulla. Most early-stage ANE cases have brain edema, and about 10\% - 20\% of them show features of acute necrotizing encephalopathy; imaging shows widespread areas of restricted diffusion in white matter [36]. Generally, using contrast-enhanced CT, which is an easy-to-obtain neuroimaging test, ring-shaped enhancement of the thalamus and deep brain white matter can be detected after 3 days in the course of illness, irregular high-density shadows in the hypothalamic mottled low-density area can be observed after 7 days in the course of illness; while no abnormal lesions were found in patients who died within 30 hours [37] (Figure 2). Grey matter damage is significantly different in conventional MRI [38]: In typical cases, symmetric grey matter lesions shows decreased signal intensity in T1-weighted image (T1WI), and increased signal intensity in T2-weighted image (T2WI); 3 days after onset of encephalopathy, the thalami displays concentric-ring pattern in T1WI, that is, increased signal intensity is in the center of 


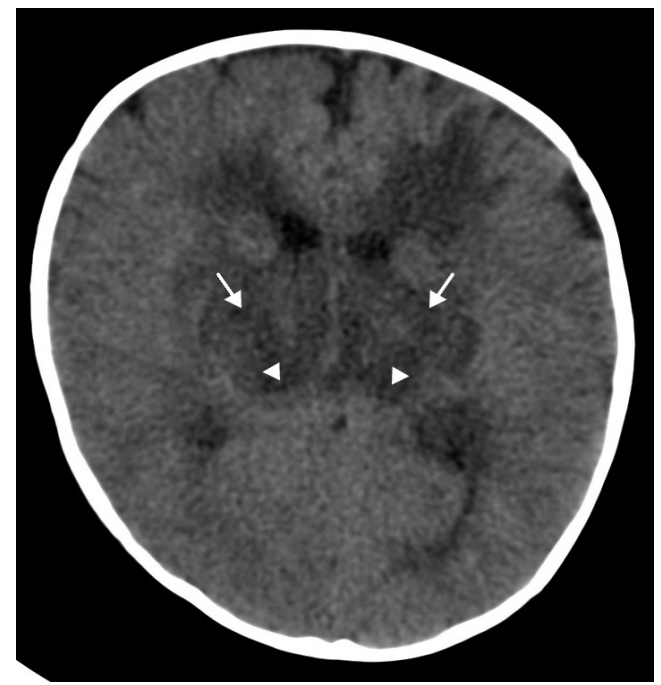

Figure 2. Acute necrotizing encephalopathy. Male, 10 months old, presented fever, cough, wheezing for 3 days, and seizures 4 times, with positive throat wrap for influenza type B. Axial CT plain scan showed bilateral basal ganglia swelling, lenticular nucleus (arrow) and adjacent white matter showed symmetrical low density, and thalamus (arrow) showed lower density.

the lesion and decreased signal intensity is in ring shape around the center, besides, increased signal intensity stilled remains in T2WI; in the second week, T1WI reveals ring-shaped increased signal intensity in the thalami, indicating subacute hemorrhage. Diffusion-weighted imaging (DWI) and apparent diffusion coefficient (ADC) map show concentric pattern in acute phase of typical cases [39], as shown in Figure 3 and Figure 4.

\subsection{Pathology}

About $70 \%$ of children with ANE died or had severe neurological dysfunction. Cadaveric brain was dissected under the light microscopy and examined with myelin and H\&E staining. The lesion showed a stratified structural change from the outside to the inside, that is, the concentric structure of the thalamic lesion [16] [37]: moderately sized plasma extravasation occurred in the vicinity of the edge of the lesion, to which the arteries were generally more susceptible than veins, and lesion areas showed myelin pallor; the surrounding tissues of central vessels (arteries, veins, and capillaries) were congested, oligodendrocytes displayed acute swelling, and the brain tissues showed loosening with increasing degree from the outside to the inside; the central blood vessels were damaged, erythrocyte extravasation was accompanied with necrosis of neuron and glial cells, but not with inflammatory cell infiltration and reactive proliferation of glial cells. A post-mortem examination of one fatal case revealed vasogenic brain edema with generalized vasculopathy, suggesting that the generalized impairment of vascular endothelial cells caused by highly activated cytokines plays a central role in the pathophysiology of this disease [14]. Extensive disruption of astrocytic projections (clasmatodendrosis) was detected in H1N1-associated deceased patients by 

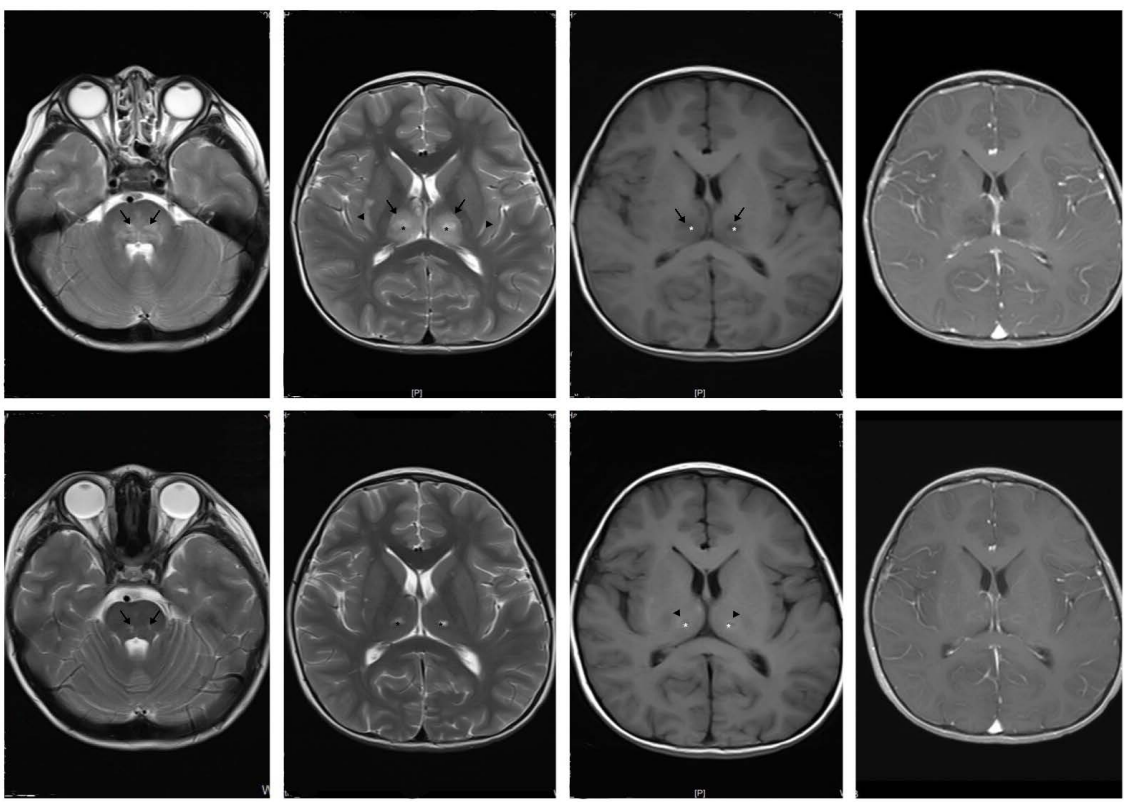

Figure 3. 7-year-old male had cough and rhinorrhea for 2 days, and could not stand stable for half day, with positive throat swab for influenza type B. (a-d) First medical examination: (a) Axial T2WI MRI indicates slightly higher focal signal intensity in the dorsal brainstem (arrow). (b) Axial T2WI MRI indicates slightly higher symmetric signal intensity in bilateral thalami (arrow), with even higher capsule-like signal intensity in center ${ }^{*}$ ), and slightly higher signal intensity in bilateral external capsules (arrow). (c) Axial T1WI MRI indicates slightly lower symmetric signal intensity in bilateral thalami (arrow), with even lower capsule-like signal intensity in center $\left({ }^{*}\right)$. (d) Contrast-enhanced axial T1WI MRI indicates no significant enhancement in bilateral thalamic lesions. (e)-(h) Re-examination 21 days later: (e) Axial T2WI MRI indicates area reduction of higher focal signal intensity in dorsal brainstem (arrow). (f) Axial T2WI MRI indicates absorption of higher symmetric signal intensity in bilateral thalami and external capsules, and higher capsule-like signal intensity in center $\left(^{*}\right)$ is still visible. (g) Axial T1WI MRI indicates absorption of lower symmetric signal intensity in bilateral thalami; lower capsule-like signal intensity in center $\left(^{*}\right)$ is still visible, and ring-like slightly higher signal intensity at the edge (arrow). (h) Contrast-enhanced axial T2WI MRI indicates no significant enhancement of bilateral thalamic lesions.

anti-glial fibrillary acidic protein (GFAP) immunostaining of brain tissue [30]. The pathological changes of the above parts can also be observed in the anatomy of patients with IAE, which suggested there might be overlap or confusion in the diagnosis between IANE and IAE.

\subsection{Diagnostic Criteria, Treatment and Outcome}

As reported showed, the present studies did not find indicators of IANE diagnosis from laboratory indicator [16] [35]. Mizuguchi et al. proposed diagnostic criteria for ANE for clinical reference [16] (Table 2): 1) Determination of influenza; 2) Clinical manifestations of acute encephalopathy immediately after influenza infection, including convulsion, rapid cognitive impairment, mental status changes, decrease in consciousness, and coma; 3) Normal number of cells and increased amount of proteins $(>0.4 \mathrm{~g} / \mathrm{L})$ in cerebrospinal fluid; 4) Symmetric multiple 


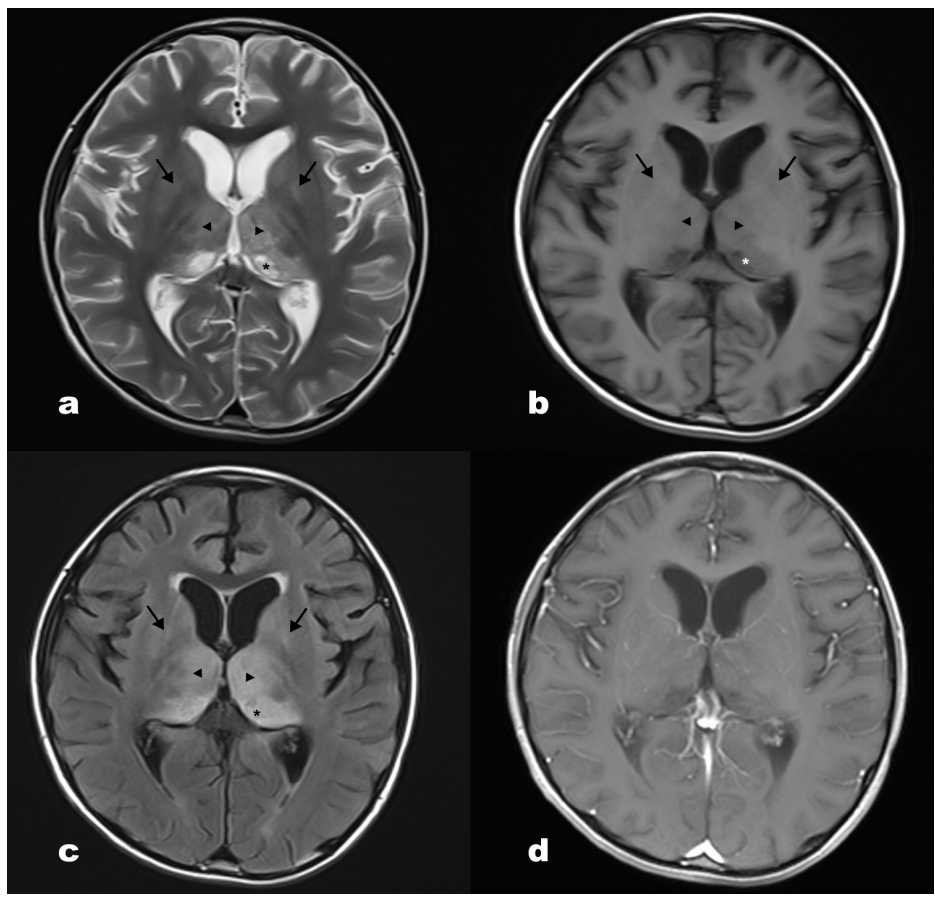

Figure 4. Acute necrotizing encephalopathy. Male, 9 years old, fever for 20 days, convulsions with unconsciousness for 18 days. Throat swabs were positive for influenza type $B$. MRI scans showed bilateral symmetrical thalamic (arrow) and lenticular nucleus (arrow) signs of slightly swollen symmetrical abnormalities, axial T2WI (a) and T2-FLAIR (c) showed slightly higher signals, and T1WI (b) showed slightly higher signals. High signal, with central necrosis ${ }^{*}$ ), showing typical concentric changes of ANE; enhanced T1WI (d) showed no enhancement of the above lesions.

Table 2. Diagnostic and therapeutic criteria of IANE [16].

\begin{tabular}{|c|c|c|}
\hline & Criteria & Description \\
\hline 1 & $\begin{array}{l}\text { Positive diagnosis of } \\
\text { influenza }\end{array}$ & Virus antigen and nucleic acid, virus isolation \\
\hline 2 & Clinical manifestations & $\begin{array}{l}\text { Convulsions, rapid cognitive impairment, mental changes, } \\
\text { ADOC, and coma }\end{array}$ \\
\hline 3 & Laboratory & $\begin{array}{l}\text { CSF-protein level is increased }(>0.4 \mathrm{~g} / \mathrm{L}) \text {; } \\
\text { Serum ALT/AST/LDH/CK are increased to varying degrees; } \\
\text { Without hyperammonia and hypoglycemia }\end{array}$ \\
\hline 4 & Brain imaging & $\begin{array}{l}\text { Symmetrical multiple lesions including thalamus; } \\
\text { can involve the upper brainstem cover, white matter around } \\
\text { the lateral ventricle, cerebellar medulla, inner capsule, } \\
\text { putamen, and other areas of the center }\end{array}$ \\
\hline 5 & Unexplained brain dysfunction & $\begin{array}{l}\text { Diagnosis according to clinical manifestations: overwhelming } \\
\text { bacterial and viral infections, fulminant hepatitis, toxic shock, } \\
\text { hemolytic-uremic syndrome, Reye's syndrome, heat stroke } \\
\text { and encephalopathy syndrome } \\
\text { Diagnosis based on imaging examination: subacute } \\
\text { necrotizing encephalopathy, glutaric acidemia, infantile } \\
\text { striatal necrosis, Wernicke's encephalopathy, carbon } \\
\text { monoxide poisoning, acute disseminated encephalomyelitis } \\
\text { (ADEM), acute necrotizing hemorrhagic encephalopathy and } \\
\text { others types of encephalitis and vasculitis }\end{array}$ \\
\hline
\end{tabular}




\section{Continued}

a) Timely detection and early treatment, Maintain vital signs,
Intensive care
b) Best treatment practice
control temperature, reduce cerebral edema
c) Antiviral treatment: Oseltamivir, peramivir, Zanamivir, etc.
d) Immunoglobulin, glucocorticoids, and plasma exchange

lesions in neuroimaging test in areas including thalamus and possibly involving upper brainstem tegmentum, peri-ventricular white matter, cerebellar medulla, internal capsule, and putamen nucleus, but not other areas in the central nervous system; 5) Increase of serum transaminase with varying degrees, with possible absence of hyperammonemia and hypoglycemia; 6) Brain dysfunction that cannot be explained by other diseases, including 1) Diagnosis according to clinical manifestations: overwhelming bacterial and viral infections, fulminant hepatitis, toxic shock, hemolytic-uremic syndrome, Reye's syndrome, heat stroke and encephalopathy syndrome, and 2) Diagnosis based on imaging examination: subacute necrotizing encephalopathy, glutaric acidemia, infantile striatal necrosis, Wernicke's encephalopathy, carbon monoxide poisoning, acute disseminated encephalomyelitis (ADEM), acute necrotizing hemorrhagic encephalopathy and others types of encephalitis and vasculitis. Mortality rate of ANE is around 30\%, and one third of survivals have neurological sequelae [14]. Common treatments include intensive care to maintain vital signs, low brain temperature, maintain cerebral perfusion, control temperature, reduce cerebral edema, oseltamivir, immunoglobulin, glucocorticoids, and plasma exchange [40] [41] (Table 2). Despite the consensus treatment, including immunoglobulins and intravenous steroids, the patients with IANE still had high rates of mortality (around 30\%) and sequelae (33\% to 50\%). Oseltamivir did not help to avoid death [42].

\subsection{Basic Research Progress}

At present, the mechanism of nerve cell necrosis in patients with IANE is still unclear.

\subsubsection{Viral Factors}

The most common pathogens of IAE and ANE have been proven to be pandemic influenza viruses (H3N2 strain, H1N1 strain) [14] [16] [34].

\subsubsection{Inflammatory Factors}

Previous studies have detected elevated plasma and cerebrospinal fluid levels of pro-inflammatory cytokines and their receptors, such as tumor necrosis factor $\alpha$, interleukin-6 and soluble TNF receptor 1 [43] [44] [45] [46]. Research of Hosoya and colleagues indicates that elevated serum level of cytochrome $c$ in permeability along with cell death induce release of cytochrome $c$ into the cytoplasm, promote caspase activation mediated by apoptotic protease activating factor 1 (Apaf-1), which triggers cell apoptosis; excessive activation of caspase could also lead to cell necrosis [47]. In addition, CSF diacron-reactive oxygen metabolites (Dia- 
cron-Reactive Oxygen Metabolites, CSF d-ROM) levels were elevated in patients with severe brain injuries, which could be valid indicators of IAE severity [48]. These phenomena indicate that influenza virus infections is accompanied by elevated levels of inflammatory cytokines; some inflammatory cytokines, such as cytochrome c oxidase, are indicative for incidence of IAE and ANE; The elevated CSF d-ROM implies that increased oxidised stress may be relevant to the pathogenesis of IAE and ANE. Nerve cell necrosis is an essential pathological change in IANE. As necrotic nerve cells increase, necrosis-associated biomarker levels are reflected in CSF, including LDH [49] and MDA, however no related literature was reported.

\subsubsection{Autoimmune Factors}

Autoimmune encephalopathy is one of the complications of influenza-related brain injuries [8] [50]. There were tests in pathological brain tissues from autopsies and rat models were positive for antibodies to aquaporin-4 (AQP4) [25] [51]; and clasmatodendrosis was distributed diffusely in the brains tissue in close association with synapses, and was not caused by astrocyte autophagy [25]. There has been research showing that influenza viruses may promote type I $\mathrm{T}$ cell infiltration into CNS, thus inducing long-term exacerbation of autoimmune encephalomyelitis [52]. Neopterin concentrations in cerebrospinal fluid were elevated in patients with IAE [26], which are markers of cellular immune activation [53] [54]. These studies suggest that influenza viruses cause immune damage and persistence of neuropathy through different pathways by stimulating the formation of autoantibodies.

\subsubsection{Vascular Endothelial Damage Factors}

Imaging study showed deep cerebral venous thrombosis in ANE patients, and attenuated signal intensity and enlarged deep cerebral veins in brain T2-weighted MR [13]. Brain pathology of deceased influenza patients found vascular lesions in nervous system, such as cerebral vascular occlusions, microthrombus formation, perivascular hemorrhage [23] [24]; there also existed apoptosis of vascular endothelial cell and brain tissue [55] [56]. Studies have shown that both platelet-derived growth factor (PDGF) and vascular endothelial growth factor (VEGF) levels were elevated in IAE patients, while elevation of PDGF was more significant and correlated with incidence and prognosis of ANE [57].

\subsubsection{Host Gene Tendency Factors}

There are reports indicating that hosts with certain genetic mutations displayed higher incidence of influenza and even ANE. Polymorphism in the ran-binding protein 2 (RANBP2) gene is associated with recurrent necrotizing encephalitis and respiratory viral infection [15]. There are some other reports indicating higher risk of severe IAE in patients with mutations in the interleukin 10 receptor, alpha subunit (IL-10RA) [58]. Researchers believe that mutations in the CYP2C9 gene are possibly involved with diclofenac-induced IAE [59]. These abnormalities are rarely seen, but their correlation with incidence of ANE cannot be ignored. 


\section{Influenza-Associated Acute Encephalitis}

\subsection{Epidemiology and Susceptible Population}

There are few epidemiological reports of influenza-associated acute encephalitis. Vulnerable populations in different countries and regions are also different. For example, most severe in France occur in adults, while in East Asia, children are more common but different in age [60].

\subsection{Clinical Manifestation}

The clinical manifestations of influenza-associated acute encephalitis are similar to IAE, which presenting convulsions, acute cognitive impairment, acute disturbance of consciousness (ADOC), and coma with varying severity [14] [15] [16] [60]. The two are difficult to distinguish from clinical manifestations.

\subsection{Laboratory Inspection}

Influenza-associated acute encephalitis should be taken into consideration when excessive high level of leukocyte is detected in the cerebrospinal fluid (CSF) [10]. Protein level in CSF is generally normal or slightly increased, while ANE is accompanied with increased protein level in CSF, and non-increasing level of leukocyte.

\subsection{Imaging Examination}

Brain images show changes in viral encephalitis/meningitis [22] [61], such as cerebral edema and meningeal strengthening. Changes in the brain imaging of the IAE could be observed, and no abnormalities could Changes in the brain imaging of the IAE were also observed, and no abnormalities could also be observed.

\subsection{Diagnostic Criteria, Treatment and Outcome}

Encephalitis was defined as encephalopathy plus two or more of the following [28] [62] (Table 3): 1) having laboratory-confirmed novel influenza virus infection with seizures, encephalopathy, or encephalitis within 5 days of influenza-like illness symptom onset, without evidence of an alternative etiology; 2) Encephalopathy was defined as altered mental status lasting $\geq 24$ hours; 3) Encephalitis was defined as encephalopathy plus two or more of the following: fever $\geq 100.4^{\circ} \mathrm{F}$ $\left(\geq 38.0^{\circ} \mathrm{C}\right.$ ), focal neurologic signs, cerebrospinal fluid pleocytosis (WBC $\geq 5 / \mathrm{uL}$ ), an electroencephalogram indicative of encephalitis, or abnormal neuroimaging indicative of infection or inflammation. In addition to anti-influenza virus treatment, symptomatic treatment are generally given, such as close monitoring and evaluation, stabilization of water and electrolyte balance, control of convulsions, and relief of cerebral edema. Based on the available evidence, it is not recommended to routinely use adjuvant therapy to treat children with encephalitis, including glucocorticoids, plasma exchangwe, intravenous immunoglobulins, interferon 
Table 3. Diagnostic and therapeutic criteria of influenza-associated acute encephalitis.

\begin{tabular}{|c|c|c|}
\hline & Criteria & Description \\
\hline \multirow{7}{*}{1} & \multirow{7}{*}{$\begin{array}{c}\text { Diagnostic } \\
\text { (Encephalitis is defined } \\
\text { as a, b plus two or } \\
\text { more terms of } \mathrm{c}-\mathrm{g} \text { ) }\end{array}$} & a) The test was positive for the flu virus \\
\hline & & b) Encephalopathy \\
\hline & & c) fever $\geq 100.4^{\circ} \mathrm{F}\left(\geq 38.0^{\circ} \mathrm{C}\right)$ \\
\hline & & d) Local nervous system examination was positive \\
\hline & & $\begin{array}{l}\text { e) Cerebrospinal fluid pleocytosis (WBC } \geq 5 / \mathrm{uL} \text {, Lymphocyte } \\
\text { predominance) }\end{array}$ \\
\hline & & $\begin{array}{l}\text { f) The EEG showed persistent diffuse slow wave changes in } \\
\text { the background }\end{array}$ \\
\hline & & $\begin{array}{l}\text { g) Abnormal neuroimaging indicative of infection or } \\
\text { inflammation }\end{array}$ \\
\hline \multirow{4}{*}{2} & \multirow{4}{*}{ Best treatment practice } & $\begin{array}{l}\text { a) Active treatment of primary disease: Early antiviral) In } \\
\text { severe cases, the dose can be doubled and the course of } \\
\text { treatment prolonged }\end{array}$ \\
\hline & & b) Support treatment and prevention of further damage: \\
\hline & & $\begin{array}{l}\text { Control the state of convulsion, ensure sufficient heat and } \\
\text { energy metabolism, and maintain the stability of internal } \\
\text { environment, Ventilator assisted ventilation, temperature } \\
\text { control and intracranial pressure }\end{array}$ \\
\hline & & $\begin{array}{l}\text { c) Immune regulation and blood purification are not routinely } \\
\text { recommended }\end{array}$ \\
\hline
\end{tabular}

alpha, and therapeutic hypothermia [63] [64] [65]. Most of the patients with Influenza-associated acute encephalitis have good recovery. The poor prognosis is related to the following factors: coma, convulsions, or focal neurological manifestations during the acute phase; younger ( $<5$ years); needs intensive care; MRI shows limited diffusion [66] [67].

\section{Post-Influenzal Encephalitis (PIE)}

\subsection{Epidemiology and Susceptible Population}

During the influenza outbreak, abnormal behaviors such as personality changes and delirium occur in around $10 \%$ of influenza patients in the recovery period or after $2-3$ weeks since the onset of influenza, in which circumstance attention should be paid to the possible PIE [68] [69] [70]. This situation can also happen now after flu vaccination. Children and adolescents are more common.

\subsection{Clinical Manifestation}

PIE can be found in a variety of clinical manifestations such as autoimmune encephalitis, limbic encephalitis, and acute disseminated encephalomyelitis (ADEM); some patients may develop Guillain-Barre syndrome [71]. After 2 - 3 weeks since the onset of influenza, most PIE patients without fever, and display convulsions, delirium, hallucinations, gibberish, personality changes, limb weakness or dyskinesia autonomic disorders, hypoventilation and other first-episode neuropsychiatric symptoms. 


\subsection{Laboratory Inspection}

Encephalitis-like cerebrospinal fluid changes could be found. Positive autoantibody test result, such as anti-NMDAR antibody-positive detection [70] [72], can be found in some PIE patients.

\subsection{Imaging Examination}

Typical MRI manifestations of post-infection encephalitis include multifocal white matter lesions. Long T2 signal in cortical lesions is detected by brain MRI in PIE patients.

\subsection{Diagnostic Criteria, Treatment and Outcome}

Children and adolescents with psychiatric symptoms, dyskinesias, seizures, autonomic disorders, and hypoventilation in 2 weeks after the occurrence of influenza or vaccination need to consider this disease. Most patients can be treated initially with intravenous methylprednisolone and intravenous immunoglobulin (IVIG) (e.g., $400 \mathrm{mg} / \mathrm{kg}$ daily for 5 days) or plasma exchange. PIE currently has no definite diagnostic criteria; the diagnostic conditions and treatment measures can be referred to Table 4 .

\subsection{Basic Research Progress}

PIE is an autoimmune process, which is thought to be associated with demyelination and vascular disease [50]. There have been reports of one-way optic neuromyelitis (NMO) in patients with influenza $\mathrm{A}$ infections [73]; influenza virus infection is aggravated as neurological diseases including multiple sclerosis (MS) [74]; strengthened immunization during the epidemic seasons appears to protect patients with certain autoimmune diseases against worsening of underlying disease [75]. Autoantibodies could be detected in following patients: levels of serum antibodies against myelin-oligodendrocyte glycoprotein (MOG antibody) is elevated in patients with localized symptoms [76].

Table 4. Diagnostic and therapeutic criteria of PIE.

\begin{tabular}{|c|c|c|}
\hline & Criteria & Description \\
\hline 1 & Positive diagnosis of influenza & Influenza infection is surely present \\
\hline 2 & Clinical manifestations & $\begin{array}{l}\text { Neuropsychiatric symptoms appear for the first time during } \\
\text { the recovery from influenza or } 2 \text { to } 3 \text { weeks after the onset } \\
\text { of influenza: personality changes, seizures, delirium, } \\
\text { hallucinations, gibberish, limb weakness or dyskinesia, etc. }\end{array}$ \\
\hline 3 & Laboratory & $\begin{array}{l}\text { CSF cell number increased, lymphocyte hyperplasia, protein } \\
\text { can be slightly increased or normal }\end{array}$ \\
\hline 4 & Brain imaging & The EEG may show diffuse slow electrical activity \\
\hline 5 & Best treatment practice & $\begin{array}{l}\text { Intravenous immunoglobulin (IVIG) (e.g., } 400 \mathrm{mg} / \mathrm{kg} \text { daily } \\
\text { for } 5 \text { days); intravenous methylprednisolone; } \\
\text { plasma exchange }\end{array}$ \\
\hline
\end{tabular}




\section{Cerebral Infarction or Cerebrovascular Lesion}

\subsection{Epidemiology and Susceptible Population}

Cerebral infarction or cerebrovascular disease is rare after influenza virus infection in children, but common in adults. The influenza season is usually consistent with peak mortality and morbidity due to cardiovascular diseases and pneumonia. Influenza vaccination can reduce probability of infection, and therefore prevent formation of cerebral thrombosis and incidence of cerebral infarction [77] [78] [79]. Patients with high blood pressure, coronary heart disease, diabetes mellitus, hypertriglyceridemia and hypohigh-density lipoproteinemia had higher incidence of cerebral infarction after infection with influenza virus than healthy people.

\subsection{Clinical Manifestation}

There are few reports on cerebral infarction or cerebrovascular disease complicated by influenza in children. In clinical practice, if patients with influenza infection appear facial paralysis, limb movement disorders, sensory disorders, aphasia, consciousness disorders and/or accompanied by hypertension, diabetes, and the laboratory is clear influenza virus infection, at the same time with increased fibrinogen, attention should be paid to the occurrence of cerebral infarction or cerebrovascular disease. Some children with influenza also experienced complications of thrombocytosis, including cerebrovascular accident, acute coronary syndrome, deep venous thrombosis, pulmonary embolus, mesenteric thrombosis and arterial thrombosis and also hemorrhagic complications [80].

\subsection{Imaging Examination, Pathology}

The neuroimaging features of deep cerebral venous thrombosis (DCVT) may sometimes be found [38] [39]. Catheter cerebral angiogram documented vasculopathy in PRES-involved regions with areas of focal vessel dilatation and string-of-bead appearance [81]. Brain imaging studies revealed that cerebral hemorrhage and cerebral infarction lesions were consistent with autopsy studies [20] [82]. Cerebrovascular damages could be found in the cadaveric brain tissues, appearing as cerebrovascular occlusion, microthrombus formation, and perivascular hemorrhage [23] [24]. Lesion damage showed stratified structural change from the outside to the inside, which is concentric structure of thalamic lesions [16] [37].

\subsection{Diagnostic Criteria, Treatment and Outcome}

Clinical influenza complicated with cerebral infarction is often missed or misdiagnosed. For example, the delay of anticoagulant treatment due to misdiagnosis or missed diagnosis in the time window can lead to serious adverse consequences. The situation of patients with cerebral infarction or cerebrovascular disease after influenza virus infection is dangerous and the patient's laboratory indicators should be closely monitored and timely treated. In addition to active anti-virus, symptomatic support, brain function protection and other treatment, timely and 
Table 5. Diagnostic and therapeutic criteria of cerebral infarction or cerebrovascular lesion.

\begin{tabular}{|c|c|c|}
\hline & Criteria & Description \\
\hline 1 & Positive diagnosis of influenza & Influenza infection is surely present \\
\hline 2 & Clinical manifestations & $\begin{array}{l}\text { Facial paralysis, physical movement disorders, sensory } \\
\text { disorders, aphasia, consciousness disorders; often } \\
\text { accompanied by high blood pressure or diabetes }\end{array}$ \\
\hline 3 & Laboratory & $\begin{array}{l}\text { Both fibrinogen and lipid levels were elevated, } \\
\text { thrombocytosis }\end{array}$ \\
\hline 4 & Brain imaging & $\begin{array}{l}\text { Head CT/MRI or Cerebral angiography revealed } \\
\text { lesion of cerebral infarction, cerebral hemorrhage }\end{array}$ \\
\hline 5 & Best treatment practice & $\begin{array}{l}\text { a) General treatment: Ensure adequate oxygen supply; } \\
\text { control blood pressure and blood glucose reasonably; } \\
\text { control the temperature and maintain internal stability } \\
\text { b) Special treatment: Fibrinolytic therapy; } \\
\text { platelet inhibitor therapy; anticoagulation } \\
\text { c) Prevention and treatment of complications } \\
\text { d) Treatment of increased intracranial pressure } \\
\text { and brain edema }\end{array}$ \\
\hline
\end{tabular}

effective thrombolysis and anticoagulant treatment is particularly important, but also through influenza vaccination can reduce infection to prevent cerebral thrombosis and the occurrence of cerebral infarction. As shown in Table 5, the occurrence of cerebral infarction or cerebrovascular lesions should be warned.

\section{Conclusion}

Influenza is accompanied by various brain lesion complications in different stages of the disease: Acute symptoms, such as convulsions, cognitive impairment, ADOC and coma, could occur in the acute phase; mental symptoms could be seen in the recovery period, such as deliriums, hallucinations and personality changes. Some neurological complications are life-threatening or leave severe neurological sequelae, such as acute necrotizing encephalopathy. Therefore, clinicians should be vigilant to early diagnosis and reasonable intervention. Studies have shown that in addition to viruses and hosts, there are other factors in the pathogenesis of influenza-associated brain injuries, such as inflammation, autoimmunity and cerebral vascular endothelial damage, yet the precise pathogenesis remains to be further elucidated.

\section{Acknowledgements}

This work was supported by: National Natural Science Foundation of China (No. 81801206); the Medical Science and Technology Research Foundation of Guangdong, China (No. A2019373); Innovative Project of Children's Research Institute, Guangzhou Women and Children's Medical Center, China (No. Pre-NSFC-2018-004, Pre-NSFC-2018-008, and IP-2018-006). 


\section{Conflicts of Interest}

The authors declare no conflicts of interest regarding the publication of this paper.

\section{References}

[1] Grohskopf, L.A., Alyanak, E., Broder, K.R., Walter, E.B., Fry, A.M. and Jernigan, D.B. (2019) Prevention and Control of Seasonal Influenza with Vaccines: Recommendations of the Advisory Committee on Immunization Practices-United States, 2019-20 Influenza Season. MMWR Recommendations and Reports, 68, 1-21. https://doi.org/10.15585/mmwr.rr6803a1

[2] Jochems, S.P., Marcon, F., Carniel, B.F., Holloway, M., Mitsi, E., Smith, E., Gritzfeld, J.F., Solorzano, C., Reine, J., Pojar, S., et al. (2018) Inflammation Induced by Influenza Virus Impairs Human Innate Immune Control of Pneumococcus. Nature Immunology, 19, 1299-1308. https://doi.org/10.1038/s41590-018-0231-y

[3] Azziz Baumgartner, E., Dao, C.N., Nasreen, S., Bhuiyan, M.U., Mah, E.M.S., Al Mamun, A., Sharker, M.A., Zaman, R.U., Cheng, P.Y., Klimov, A.I., et al. (2012) Seasonality, Timing, and Climate Drivers of Influenza Activity Worldwide. The Journal of Infectious Diseases, 206, 838-846. https://doi.org/10.1093/infdis/jis467

[4] Centers for Disease C, Prevention (2010) Estimates of Deaths Associated with Seasonal Influenza-United States, 1976-2007. MMWR Morbidity and Mortality Weekly Report, 59, 1057-1062.

[5] Wong, K.K., Jain, S., Blanton, L., Dhara, R., Brammer, L., Fry, A.M. and Finelli, L. (2013) Influenza-Associated Pediatric Deaths in the United States, 2004-2012. Pediatrics, 132, 796-804. https://doi.org/10.1542/peds.2013-1493

[6] Taubenberger, J.K., Reid, A.H., Krafft, A.E., Bijwaard, K.E. and Fanning, T.G. (1997) Initial Genetic Characterization of the 1918 "Spanish" Influenza Virus. Science, 275, 1793-1796. https://doi.org/10.1126/science.275.5307.1793

[7] Schotsaert, M. and Garcia-Sastre, A. (2016) A High-Resolution Look at Influenza Virus Antigenic Drift. The Journal of Infectious Diseases, 214, 982. https://doi.org/10.1093/infdis/jiw183

[8] Shah, S., Keil, A., Gara, K. and Nagarajan, L. (2014) Neurologic Complications of Influenza. Journal of Child Neurology, 29, NP49-NP53.

https://doi.org/10.1177/0883073813499610

[9] Surtees, R. and DeSousa, C. (2006) Influenza Virus Associated Encephalopathy. Archives of Disease in Childhood, 91, 455-456. https://doi.org/10.1136/adc.2005.092890

[10] Amin, R., Ford-Jones, E., Richardson, S.E., MacGregor, D., Tellier, R., Heurter, H., Fearon, M. and Bitnun, A. (2008) Acute Childhood Encephalitis and Encephalopathy Associated with Influenza: A Prospective 11-Year Review. The Pediatric Infectious Disease Journal, 27, 390-395. https://doi.org/10.1097/INF.0b013e31816507b2

[11] Hayase, Y. and Tobita, K. (1997) Influenza Virus and Neurological Diseases. Psychiatry and Clinical Neurosciences, 51, 181-184. https://doi.org/10.1111/j.1440-1819.1997.tb02580.x

[12] Fujimoto, S., Kobayashi, M., Uemura, O., Iwasa, M., Ando, T., Katoh, T., Nakamura, C., Maki, N., Togari, H. and Wada, Y. (1998) PCR on Cerebrospinal Fluid to Show Influenza-Associated Acute Encephalopathy or Encephalitis. The Lancet, 352, 873-875. https://doi.org/10.1016/S0140-6736(98)12449-2 
[13] Taniguchi, D., Nakajima, S., Hayashida, A., Kuroki, T., Eguchi, H., Machida, Y., Hattori, N. and Miwa, H. (2017) Deep Cerebral Venous Thrombosis Mimicking Influenza-Associated Acute Necrotizing Encephalopathy: A Case Report. Journal of Medical Case Reports, 11, 281. https://doi.org/10.1186/s13256-017-1444-7

[14] Togashi, T., Matsuzono, Y., Narita, M. and Morishima, T. (2004) Influenza-Associated Acute Encephalopathy in Japanese Children in 1994-2002. Virus Research, 103, 75-78. https://doi.org/10.1016/j.virusres.2004.02.016

[15] Howard, A., Uyeki, T.M. and Fergie, J. (2018) Influenza-Associated Acute Necrotizing Encephalopathy in Siblings. Journal of the Pediatric Infectious Diseases Society, 7, e172-e177. https://doi.org/10.1093/jpids/piy033

[16] Mizuguchi, M., Abe, J., Mikkaichi, K., Noma, S., Yoshida, K., Yamanaka, T. and Kamoshita, S. (1995) Acute Necrotising Encephalopathy of Childhood: A New Syndrome Presenting with Multifocal, Symmetric Brain Lesions. Journal of Neurology, Neurosurgery, and Psychiatry, 58, 555-561. https://doi.org/10.1136/jnnp.58.5.555

[17] Mastrolia, M.V., Rubino, C., Resti, M., Trapani, S. and Galli, L. (2019) Characteristics and Outcome of Influenza-Associated Encephalopathy/Encephalitis among Children in a Tertiary Pediatric Hospital in Italy, 2017-2019. BMC Infectious Diseases, 19, 1012. https://doi.org/10.1186/s12879-019-4636-5

[18] Sugaya, N. (2002) Influenza-Associated Encephalopathy in Japan. Seminars in Pediatric Infectious Diseases, 13, 79-84. https://doi.org/10.1053/spid.2002.122993

[19] Tokunaga, Y., Kira, R., Takemoto, M., Gondo, K., Ishioka, H., Mihara, F. and Hara, T. (2000) Diagnostic Usefulness of Diffusion-Weighted Magnetic Resonance Imaging in Influenza-Associated Acute Encephalopathy or Encephalitis. Brain \& Development, 22, 451-453. https://doi.org/10.1016/S0387-7604(00)00179-0

[20] Dadak, M., Pul, R., Lanfermann, H., Hartmann, H., Hehr, U., Donnerstag, F., Michels, D. and Tryc, A.B. (2019) Varying Patterns of CNS Imaging in Influenza A Encephalopathy in Childhood. Clinical Neuroradiology. https://doi.org/10.1007/s00062-018-0756-3

[21] Abenhaim Halpern, L., Agyeman, P., Steinlin, M., El-Koussy, M. and Grunt, S. (2013) Mild Encephalopathy with Splenial Lesion and Parainfluenza Virus Infection. Pediatric Neurology, 48, 252-254. https://doi.org/10.1016/j.pediatrneurol.2012.11.007

[22] Kimura, S., Ohtuki, N., Nezu, A., Tanaka, M. and Takeshita, S. (1998) Clinical and Radiological Variability of Influenza-Related Encephalopathy or Encephalitis. Acta paediatrica Japonica: Overseas Edition, 40, 264-270. https://doi.org/10.1111/j.1442-200X.1998.tb01925.x

[23] Sato, T. and Moriuchi, H. (2010) [Influenza-Associated Encephalopathy]. Nihon Rinsho Japanese Journal of Clinical Medicine, 68, 1661-1665.

[24] Shiomi, M. (2011) [Pathogenesis of Acute Encephalitis and Acute Encephalopathy]. Nihon Rinsho Japanese Journal of Clinical Medicine, 69, 399-408.

[25] Tachibana, M., Mohri, I., Hirata, I., Kuwada, A., Kimura-Ohba, S., Kagitani-Shimono, K., Fushimi, H., Inoue, T., Shiomi, M., Kakuta, Y., et al. (2019) Clasmatodendrosis Is Associated with Dendritic Spines and Does Not Represent Autophagic Astrocyte Death in Influenza-Associated Encephalopathy. Brain \& Development, 41, 85-95. https://doi.org/10.1016/j.braindev.2018.07.008

[26] Macdonald-Laurs, E., Koirala, A., Britton, P.N., Rawlinson, W., Hiew, C.C., McRae, J., Dale, R.C., Jones, C., Macartney, K., McMullan, B., et al. (2019) CSF Neopterin, a Useful Biomarker in Children Presenting with Influenza Associated Encephalopathy? European Journal of Paediatric Neurology: EJPN: Official Journal of the Euro- 
pean Paediatric Neurology Society, 23, 204-213. https://doi.org/10.1016/j.ejpn.2018.09.009

[27] Sejvar, J.J., Kohl, K.S., Bilynsky, R., Blumberg, D., Cvetkovich, T., Galama, J., Gidudu, J., Katikaneni, L., Khuri-Bulos, N., Oleske, J., et al. (2007) Encephalitis, Myelitis, and Acute Disseminated Encephalomyelitis (ADEM): Case Definitions and Guidelines for Collection, Analysis, and Presentation of Immunization Safety Data. Vaccine, 25, 5771-5792. https://doi.org/10.1016/j.vaccine.2007.04.060

[28] Centers for Disease C, Prevention (2009) Neurologic Complications Associated with Novel Influenza A (H1N1) Virus Infection in Children-Dallas, Texas, May 2009. MMWR Morbidity and Mortality Weekly Report, 58, 773-778.

[29] Britton, P.N., Dale, R.C., Blyth, C.C., Macartney, K., Crawford, N.W., Marshall, H., Clark, J.E., Elliott, E.J., Webster, R.I., Cheng, A.C., et al. (2017) Influenza-Associated Encephalitis/Encephalopathy Identified by the Australian Childhood Encephalitis Study 2013-2015. The Pediatric Infectious Disease Journal, 36, 1021-1026. https://doi.org/10.1097/INF.0000000000001650

[30] Yamada, S., Yasui, K., Hasegawa, Y., Tsuzuki, T., Yoshida, M. and Hashidume, Y. (2012) [An Autopsy Case of Pandemic (H1N1) 2009 Influenza Virus-Associated Encephalopathy]. Rinsho Shinkeigaku/Clinical Neurology, 52, 480-485.

https://doi.org/10.5692/clinicalneurol.52.480

[31] Yoshimura, H., Imai, Y., Beppu, M., Ohara, N., Kobayashi, J., Kuzuya, A., Yamagami, H., Kawamoto, M. and Kohara, N. (2008) [Elderly Autopsy Case of Influenza-Associated Encephalopathy]. Rinsho Shinkeigakul Clinical Neurology, 48, 713-720. https://doi.org/10.5692/clinicalneurol.48.713

[32] Sun, G., Ota, C., Kitaoka, S., Chiba, Y., Takayanagi, M., Kitamura, T., Yamamoto, K., Fujie, H., Mikami, H., Uematsu, M., et al. (2015) Elevated Serum Levels of Neutrophil Elastase in Patients with Influenza Virus-Associated Encephalopathy. Journal of the Neurological Sciences, 349, 190-195.

https://doi.org/10.1016/j.jns.2015.01.017

[33] Hosoya, M., Nunoi, H., Aoyama, M., Kawasaki, Y. and Suzuki, H. (2005) Cytochrome $\mathrm{C}$ and Tumor Necrosis Factor-Alpha Values in Serum and Cerebrospinal Fluid of Patients with Influenza-Associated Encephalopathy. Pediatric Infectious Disease Journal, 24, 467-470. https://doi.org/10.1097/01.inf.0000160995.07461.b8

[34] Weitkamp, J.H., Spring, M.D., Brogan, T., Moses, H., Bloch, K.C. and Wright, P.F. (2004) Influenza a Virus-Associated Acute Necrotizing Encephalopathy in the United States. The Pediatric Infectious Disease Journal, 23, 259-263.

https://doi.org/10.1097/01.inf.0000115631.99896.41

[35] Kondrich, J. and Rosenthal, M. (2017) Influenza in Children. Current Opinion in Pediatrics, 29, 297-302. https://doi.org/10.1097/MOP.0000000000000495

[36] Kirat, N., De Cauwer, H., Ceulemans, B., Vanneste, D. and Rossi, A. (2018) Influenza-Associated Encephalopathy with Extensive Reversible Restricted Diffusion within the White Matter. Acta Neurologica Belgica, 118, 553-555.

https://doi.org/10.1007/s13760-018-1004-y

[37] Mizuguchi, M., Hayashi, M., Nakano, I., Kuwashima, M., Yoshida, K., Nakai, Y., Itoh, M. and Takashima, S. (2002) Concentric Structure of Thalamic Lesions in Acute Necrotizing Encephalopathy. Neuroradiology, 44, 489-493. https://doi.org/10.1007/s00234-002-0773-3

[38] Ormitti, F., Ventura, E., Summa, A., Picetti, E. and Crisi, G. (2010) Acute Necrotizing Encephalopathy in a Child during the 2009 Influenza A(H1N1) Pandemia: MR Imaging in Diagnosis and Follow-up. AJNR American Journal of Neuroradiology, 
31, 396-400. https://doi.org/10.3174/ajnr.A2058

[39] Goo, H.W., Choi, C.G., Yoon, C.H. and Ko, T.S. (2003) Acute Necrotizing Encephalopathy: Diffusion MR Imaging and Localized Proton MR Spectroscopic Findings in Two Infants. Korean Journal of Radiology, 4, 61-65.

https://doi.org/10.3348/kjr.2003.4.1.61

[40] Neilson, D.E. (2010) The Interplay of Infection and Genetics in Acute Necrotizing Encephalopathy. Current Opinion in Pediatrics, 22, 751-757. https://doi.org/10.1097/MOP.0b013e3283402bfe

[41] Okumura, A., Mizuguchi, M., Kidokoro, H., Tanaka, M., Abe, S., Hosoya, M., Aiba, H., Maegaki, Y., Yamamoto, H., Tanabe, T., et al. (2009) Outcome of Acute Necrotizing Encephalopathy in Relation to Treatment with Corticosteroids and Gammaglobulin. Brain \& Development, 31, 221-227. https://doi.org/10.1016/j.braindev.2008.03.005

[42] Wolkewitz, M. and Schumacher, M. (2016) Neuraminidase Inhibitors and Hospital Mortality in British Patients with H1N1 Influenza A: A Re-Analysis of Observational Data. PLoS ONE, 11, e0160430. https://doi.org/10.1371/journal.pone.0160430

[43] Ichiyama, T., Morishima, T., Suenaga, N., Kajimoto, M., Matsubara, T. and Furukawa, S. (2005) Analysis of Serum Soluble CD40 Ligand in Patients with Influenza Virus-Associated Encephalopathy. Journal of the Neurological Sciences, 239, 53-57. https://doi.org/10.1016/j.jns.2005.07.010

[44] Ichiyama, T., Morishima, T., Isumi, H., Matsufuji, H., Matsubara, T. and Furukawa, S. (2004) Analysis of Cytokine Levels and NF-kappaB Activation in Peripheral Blood Mononuclear Cells in Influenza Virus-Associated Encephalopathy. Cytokine, 27, 31-37. https://doi.org/10.1016/j.cyto.2004.03.012

[45] Nara, A., Nagai, H., Yamaguchi, R., Yoshida, K., Iwase, H. and Mizuguchi, M. (2015) An Unusual Autopsy Case of Cytokine Storm-Derived Influenza-Associated Encephalopathy without Typical Histopathological Findings: Autopsy Case Report. American Journal of Forensic Medicine and Pathology, 36, 3-5. https://doi.org/10.1097/PAF.0000000000000129

[46] Ichiyama, T., Endo, S., Kaneko, M., Isumi, H., Matsubara, T. and Furukawa, S. (2003) Serum Cytokine Concentrations of Influenza-Associated Acute Necrotizing Encephalopathy. Pediatrics International, 45, 734-736.

https://doi.org/10.1111/j.1442-200X.2003.01822.x

[47] Brown, G.C. and Borutaite, V. (2008) Regulation of Apoptosis by the Redox State of Cytochrome C. Biochimica et Biophysica Acta, 1777, 877-881. https://doi.org/10.1016/j.bbabio.2008.03.024

[48] Yamanaka, G., Kawashima, H., Suganami, Y., Watanabe, C., Watanabe, Y., Miyajima, T., Takekuma, K., Oguchi, S. and Hoshika, A. (2006) Diagnostic and Predictive Value of CSF d-ROM Level in Influenza Virus-Associated Encephalopathy. Journal of the Neurological Sciences, 243, 71-75. https://doi.org/10.1016/j.jns.2005.11.029

[49] Franke, R.P., Fuhrmann, R., Mrowietz, C., Rickert, D., Hiebl, B. and Jung, F. (2010) Reduced Diagnostic Value of Lactate Dehydrogenase (LDH) in the Presence of Radiographic Contrast Media. Clinical Hemorheology and Microcirculation, 45, 123-130. https://doi.org/10.3233/CH-2010-1290

[50] Studahl, M. (2003) Influenza Virus and CNS Manifestations. Journal of Clinical Virology: The Official Publication of the Pan American Society for Clinical Virology, 28, 225-232. https://doi.org/10.1016/S1386-6532(03)00119-7 
[51] Asai, H., Kakita, H., Aoyama, M., Nagaya, Y., Saitoh, S. and Asai, K. (2013) Diclofenac Enhances Proinflammatory Cytokine-Induced Aquaporin-4 Expression in Cultured Astrocyte. Cellular and Molecular Neurobiology, 33, 393-400. https://doi.org/10.1007/s10571-013-9905-Z

[52] Chen, Q., Liu, Y., Lu, A., Ni, K., Xiang, Z., Wen, K. and Tu, W. (2017) Influenza Virus Infection Exacerbates Experimental Autoimmune Encephalomyelitis Disease by Promoting Type I T Cells Infiltration into Central Nervous System. Journal of Autoimmunity, 77, 1-10. https://doi.org/10.1016/j.jaut.2016.10.006

[53] Stoeck, K. and Zerr, I. (2011) Cellular Immune Activation Markers Neopterin and Beta2-Microglobulin Are Not Elevated in the Cerebrospinal Fluid of Patients with Creutzfeldt-Jakob Disease. Journal of Neuroimmunology, 233, 228-232. https://doi.org/10.1016/j.jneuroim.2010.12.003

[54] Pranzatelli, M.R., Hyland, K., Tate, E.D., Arnold, L.A., Allison, T.J. and Soori, G.S. (2004) Evidence of Cellular Immune Activation in Children with Opsoclonus-Myoclonus: Cerebrospinal Fluid Neopterin. Journal of Child Neurology, 19, 919-924. https://doi.org/10.1177/08830738040190120201

[55] Nakai, Y., Itoh, M., Mizuguchi, M., Ozawa, H., Okazaki, E., Kobayashi, Y., Takahashi, M., Ohtani, K., Ogawa, A., Narita, M., et al. (2003) Apoptosis and Microglial Activation in Influenza Encephalopathy. Acta Neuropathologica, 105, 233-239. https://doi.org/10.1007/s00401-002-0605-x

[56] Takahashi, M, Yamada, T., Nakashita, Y., Saikusa, H., Deguchi, M., Kida, H., Tashiro, M. and Toyoda, T. (2000) Influenza Virus-Induced Encephalopathy: Clinicopathologic Study of an Autopsied Case. Pediatrics International, 42, 204-214. https://doi.org/10.1046/j.1442-200x.2000.01203.x

[57] Morichi, S., Morishita, N., Takeshita, M., Ishida, Y., Oana, S., Yamanaka, G., Kashiwagi, Y. and Kawashima, H. (2017) Vascular Endothelial Growth Factor (VEGF) and Platelet-Derived Growth Factor (PDGF) Levels in the Cerebrospinal Fluid of Children with Influenza-Associated Encephalopathy. Journal of Infection and Chemotherapy, 23, 80-84. https://doi.org/10.1016/j.jiac.2016.10.007

[58] Ishige, T., Igarashi, Y., Hatori, R., Tatsuki, M., Sasahara, Y., Takizawa, T. and Arakawa, H. (2018) IL-10RA Mutation as a Risk Factor of Severe Influenza-Associated Encephalopathy: A Case Report. Pediatrics, 141, e20173548. https://doi.org/10.1542/peds.2017-3548

[59] Funato, T., Kozawa, K. and Kaku, M. (2002) [Relationship of Polymorphism in CYP2C9 to Genetic Susceptibility to Diclofenac-Induced Influenza-Virus-Associated Encephalopathy]. The Japanese Journal of Clinical Pathology, 50, 140-145.

[60] Dicky, O., Cheuret, E. and Berthomieu, L. (2014) [Severe Neurological Forms of Influenza in Children: Report on Three Cases of Severe Encephalitis in France]. Archives de Pédiatrie, 21, 514-517. https://doi.org/10.1016/j.arcped.2014.02.015

[61] Hinson, V.K. and Tyor, W.R. (2001) Update on Viral Encephalitis. Current Opinion in Neurology, 14, 369-374. https://doi.org/10.1097/00019052-200106000-00017

[62] Venkatesan, A., Tunkel, A.R., Bloch, K.C., Lauring, A.S., Sejvar, J., Bitnun, A., Stahl, J.P., Mailles, A., Drebot, M., Rupprecht, C.E., et al. (2013) Case Definitions, Diagnostic Algorithms, and Priorities in Encephalitis: Consensus Statement of the International Encephalitis Consortium. Clinical Infectious Diseases. An Official Publication of the Infectious Diseases Society of America, 57, 1114-1128. https://doi.org/10.1093/cid/cit458

[63] Cherry, J.D., Harrison, G.J. and Kaplan, S.L. (2014) Feigin and Cherry's Textbook of Pediatric Infectious Diseases. 
[64] Tunkel, A.R., Glaser, C.A., Bloch, K.C., Sejvar, J.J., Marra, C.M., Roos, K.L., Hartman, B.J., Kaplan, S.L., Scheld, W.M., Whitley, R.J., et al. (2008) The Management of Encephalitis: Clinical Practice Guidelines by the Infectious Diseases Society of America. Clinical Infectious Diseases: An Official Publication of the Infectious Diseases Society of America, 47, 303-327. https://doi.org/10.1086/589747

[65] Kawano, G., Iwata, O., Iwata, S., Kawano, K., Obu, K., Kuki, I., Rinka, H., Shiomi, M., Yamanouchi, H., Kakuma, T., et al. (2011) Determinants of Outcomes Following Acute Child Encephalopathy and Encephalitis: Pivotal Effect of Early and Delayed Cooling. Archives of Disease in Childhood, 96, 936-941. https://doi.org/10.1136/adc.2009.180554

[66] Michaeli, O., Kassis, I., Shachor-Meyouhas, Y., Shahar, E. and Ravid, S. (2014) Long-Term Motor and Cognitive Outcome of Acute Encephalitis. Pediatrics, 133, e546-e552. https://doi.org/10.1542/peds.2013-3010

[67] Fowler, A., Stodberg, T., Eriksson, M. and Wickstrom, R. (2010) Long-Term Outcomes of Acute Encephalitis in Childhood. Pediatrics, 126, e828-e835. https://doi.org/10.1542/peds.2009-3188

[68] Takanashi, J., Tada, H., Kuroki, H. and Barkovich, A.J. (2009) Delirious Behavior in Influenza Is Associated with a Reversible Splenial Lesion. Brain \& Development, 31, 423-426. https://doi.org/10.1016/j.braindev.2008.07.013

[69] Okuno, H., Yahata, Y., Tanaka-Taya, K., Arai, S., Satoh, H., Morino, S., Shimada, T., Sunagawa, T., Uyeki, T.M. and Oishi, K. (2018) Characteristics and Outcomes of Influenza-Associated Encephalopathy Cases Among Children and Adults in Japan, 2010-2015. Clinical Infectious Diseases. An Official Publication of the Infectious Diseases Society of America, 66, 1831-1837. https://doi.org/10.1093/cid/cix1126

[70] Takanashi, J., Takahashi, Y., Imamura, A., Kodama, K., Watanabe, A., Tominaga, K., Muramatsu, K. and Barkovich, A.J. (2012) Late Delirious Behavior with 2009 H1N1 Influenza: Mild Autoimmune-Mediated Encephalitis? Pediatrics, 129, e1068-e1071. https://doi.org/10.1542/peds.2010-3221

[71] Utumi, Y., Iseki, E., Murayama, N., Ichimiya, Y. and Arai, H. (2010) [Limbic Encephalitis Caused by Herpes Simplex Virus Infection after Vaccination against the Influenza Virus]. Brain and Nerves, 62, 615-619.

[72] Thampi, N., Bitnun, A., Banner, D., Rowe, T., Kelvin, D.J., Richardson, S.E., Parkin, P. and Tran, D. (2011) Influenza-Associated Encephalopathy with Elevated Antibody Titers to Pandemic (H1N1) 2009 Influenza. Journal of Child Neurology, 26, 501-506. https://doi.org/10.1177/0883073810381128

[73] Nakamura, Y., Ikeda, K., Yoshii, Y., Ito, H., Hirayama, T., Kawabe, K., Kano, O. and Iwasaki, Y. (2011) Influenza-Associated Monophasic Neuromyelitis Optica. Internal Medicine, 50, 1605-1609. https://doi.org/10.2169/internalmedicine.50.5027

[74] Blackmore, S., Hernandez, J., Juda, M., Ryder, E., Freund, G.G., Johnson, R.W. and Steelman, A.J. (2017) Influenza Infection Triggers Disease in a Genetic Model of Experimental Autoimmune Encephalomyelitis. Proceedings of the National Academy of Sciences of the United States of America, 114, E6107-E6116. https://doi.org/10.1073/pnas.1620415114

[75] Muller, R.B., Maier, R., Hoschler, K., Zambon, M., Ludewig, B., Herrmann, M., Schulze-Koops, H. and von Kempis, J. (2013) Efficient Boosting of the Antiviral T Cell Response in B Cell-Depleted Patients with Autoimmune Rheumatic Diseases Following Influenza Vaccination. Clinical and Experimental Rheumatology, 31, 723-730.

[76] Amano, H., Miyamoto, N., Shimura, H., Sato, D.K., Fujihara, K., Ueno, S., Nakamura, R., Ueno, Y., Watanabe, M., Hattori, N., et al. (2014) Influenza-Associated MOG Antibody-Positive Longitudinally Extensive Transverse Myelitis: A Case Re- 
port. BMC Neurology, 14, 224. https://doi.org/10.1186/s12883-014-0224-x

[77] Puig-Barbera, J., Diez-Domingo, J., Varea, A.B., Chavarri, G.S., Rodrigo, J.A., Hoyos, S.P. and Vidal, D.G. (2007) Effectiveness of MF59-Adjuvanted Subunit Influenza Vaccine in Preventing Hospitalisations for Cardiovascular Disease, Cerebrovascular Disease and Pneumonia in the Elderly. Vaccine, 25, 7313-7321. https://doi.org/10.1016/j.vaccine.2007.08.039

[78] Lavallee, P., Perchaud, V., Gautier-Bertrand, M., Grabli, D. and Amarenco, P. (2002) Association between Influenza Vaccination and Reduced Risk of Brain Infarction. Stroke, 33, 513-518. https://doi.org/10.1161/hs0202.102328

[79] Carels, T. and Flamaing, J. (2005) [Vaccination of the Elderly: An Update]. Tijdschrift voor Gerontologie en Geriatrie, 36, 203-208. https://doi.org/10.1007/BF03074734

[80] Al Shibli, A., Alkuwaiti, N., Hamie, M., Abukhater, D., Noureddin, M.B., Amri, A., Al Kaabi, S., Al Kaabi, A., Harbi, M. and Narchi, H. (2017) Significance of Platelet Count in Children Admitted with Bronchiolitis. World Journal of Clinical Pediatrics, 6, 118-123. https://doi.org/10.5409/wjcp.v6.i2.118

[81] Bartynski, W.S., Upadhyaya, A.R. and Boardman, J.F. (2009) Posterior Reversible Encephalopathy Syndrome and Cerebral Vasculopathy Associated with Influenza A Infection: Report of a Case and Review of the Literature. Journal of Computer Assisted Tomography, 33, 917-922. https://doi.org/10.1097/RCT.0b013e3181993a43

[82] Chow, F.C., Edlow, B.L., Frosch, M.P., Copen, W.A. and Greer, D.M. (2011) Outcome in Patients with H1N1 Influenza and Cerebrovascular Injury Treated with Extracorporeal Membrane Oxygenation. Neurocritical Care, 15, 156-160.

https://doi.org/10.1007/s12028-011-9534-7 


\section{Abbreviations}

ADC: Analog-to-Digital Converter

ADEM: acute disseminated encephalomyelitis

ADOC: Acute disturbance of consciousness

ANE: acute necrotizing encephalopathy

Apaf-1: Apoptotic protease activating factor 1

AQP4: Aquaporin-4

BMI: Body Mass Index

CDC: Centers for Disease Control

CNS: central nervous system

CSF: cerebral spinal fluid

d-ROM: Diacron-Reactive Oxygen Metabolites

DWI: Diffusion weighted imaging

EEG: electroencephalogram

FC: febrile convulsion

GFAP: glial fibrillary acidic protein

HA: Hemagglutinin

HIV: Human immunodeficiency virus

IAE: Influenza-associated acute encephalitis

IAE: influenza-associated encephalopathy

IL-10RA: Interleukin 10 receptor alpha

MERS: mild encephalopathy with a reversible splenial lesion

MOG: myelin oligodendrocyte glycoprotein

MS: multiple sclerosis

NA: Neuraminidase

NASBA: Nucleic acid sequence-based amplification

NMDAR: N-methyl-D-aspartic acid receptor

NMO: neuromyelitisoptica

PDGF: platelet-derived growth factor

PIE: Post-influenza encephalitis

RanBP2: Ran binding protein 2

RT-PCR: Reverse Transcription-Polymerase Chain Reaction

VEGF: Vascular endothelial growth factor

VGKC: Voltage gated potassium channel 